\title{
Erratum to: Bone geometry, bone mineral density, and micro-architecture in patients with myelofibrosis: a cross-sectional study using DXA, HR-pQCT, and bone turnover markers
}

\author{
Sarah Farmer ${ }^{1} \cdot$ Hanne Vestergaard ${ }^{1} \cdot$ Stinus Hansen $^{2} \cdot$ Vikram Vinod Shanbhogue $^{2} \cdot$ \\ Claudia Irene Stahlberg ${ }^{3}$ Anne Pernille Hermann ${ }^{2} \cdot$ Henrik Frederiksen ${ }^{1,4}$
}

Published online: 13 August 2015

(C) The Japanese Society of Hematology 2015

\section{Erratum to: Int J Hematol (2015) 102:67-75}

DOI 10.1007/s12185-015-1803-3

The correct name of the co-author should be Vikram Vinod Shanbhogue, and not Vikram Vinod Shanbhoque as given in the original publication of the article.

The online version of the original article can be found under doi:10.1007/s12185-015-1803-3.

Sarah Farmer mailtilsarah@yahoo.com

1 Department of Haematology, Odense University Hospital, Sdr. Boulevard 29, 5000 Odense C, Denmark

2 Department of Endocrinology, Odense University Hospital, Odense, Denmark

3 Department of Pathology, Section of Haemapathology, Odense University Hospital, Odense, Denmark

4 Department of Clinical Epidemiology, Aarhus University Hospital, Aarhus, Denmark 